\title{
What Transparency Can Do When \\ Incentives Fail: An Analysis of Rent Capture
}

Era Dabla-Norris and Elisabeth Paul 



\title{
IMF Working Paper
}

Middle East and Central Asia Department

What Transparency Can Do When Incentives Fail: An Analysis of Rent Capture

\author{
Prepared by Era Dabla-Norris and Elisabeth Paul ${ }^{1}$
}

Authorized for distribution by John Wakeman-Linn

June 2006

\begin{abstract}
This Working Paper should not be reported as representing the views of the IMF. The views expressed in this Working Paper are those of the author(s) and do not necessarily represent those of the IMF or IMF policy. Working Papers describe research in progress by the author(s) and are published to elicit comments and to further debate.

This paper analyzes the pervasiveness and persistence of rent seeking, misgovernance, and public sector inefficiency in many developing and transition economies. We formalize evidence from country experiences and empirical studies into a stylized analytical framework that reflects realistic constraints faced in these countries. Our work departs from the standard economic literature by assuming that (i) the relationship between the government and its population is regulated through an implicit social consensus; (ii) traditional incentives (in the form of public expenditure controls, sanctions, or monetary incentives to perform) are, for various reasons, ineffective in many of these countries; and (iii) the persistence of high corruption reflects a very stable equilibrium, which in turn reflects the fact that several constraints are simultaneously binding. We argue that, when traditional incentives fail, transparency - information provision and disclosure, together with the means to use it - by relaxing different constraints, can contribute to improving public outcomes.
\end{abstract}

JEL Classification Numbers: D73, K42, O17

Keywords: Rent seeking, incentives, transparency

Author(s) E-Mail Address: edablanorris@imf.org; e.paul@ulg.ac.be

\footnotetext{
${ }^{1}$ Elisabeth Paul is an FNRS Research Fellow at the University of Liege.
} 


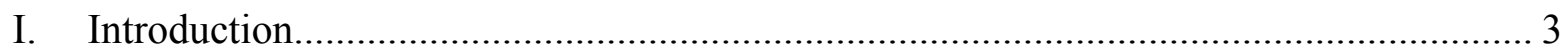

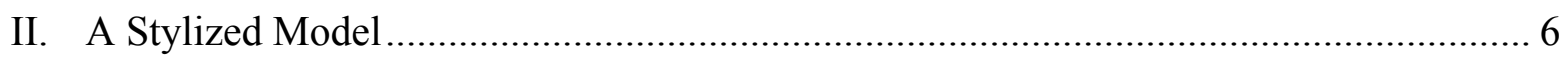

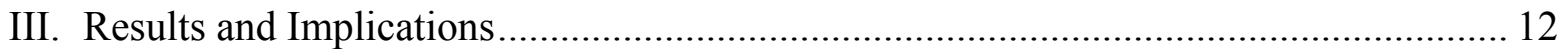

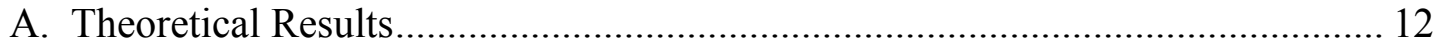

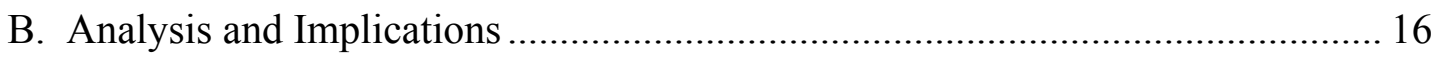

IV. The Role of Tansparency .............................................................................. 18

A. Effect on the Minimum Requirement Constraint........................................... 18

B. Effect on the Participation Constraint .............................................................. 19

C. Effect on the Budget Constraint ............................................................. 20

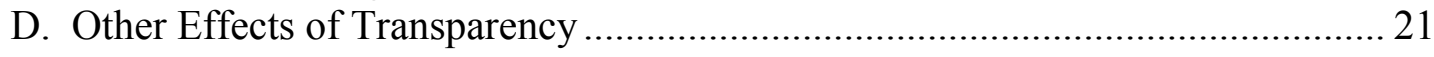

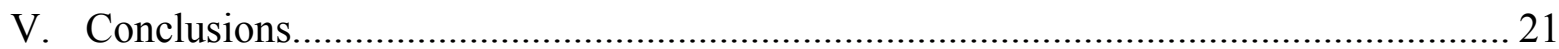

Appendix

Principal and Agent's Maximization Problems ....................................................... 23

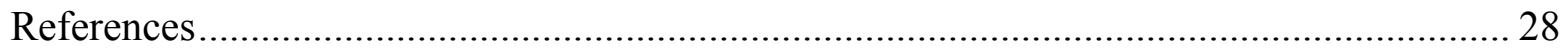




\section{INTRODUCTION}

Lack of economic development, stagnant growth, procedural ineffectiveness and inefficiency, rent seeking, and bureaucratic capture in public programs are common features of many developing and transition economies. ${ }^{2}$ Cross-country studies find that corruption is detrimental to capital accumulation, growth, and poverty reduction (Mauro, 1995; Kaufmann and Kraay, 2002). At the same time, it is increasingly recognized that corruption, once entrenched, is difficult to eliminate; for example, see Andvig and Moene (1990), DablaNorris and Freeman (2004), and Mauro(2004). ${ }^{3}$ Future reform programs designed to combat corruption and improve public sector efficiency may benefit from a better understanding of why corruption persists.

The importance of taking account of the institutional settings and incentive structures for fighting corruption is increasingly recognized both by practitioners (World Bank, 1997; IMF, 2003, 2005) and theoreticians (Shleifer and Vishny, 1993; Acemoglu and Verdier, 2000; and Dabla-Norris, 2002). However, there is often a gap between theory and practice. Since the seminal contributions of Becker and Stigler (1974) and Rose-Ackerman (1978), corruption has often been studied in a principal-agent framework where the principal (the government or citizens) tries to motivate the agent (public agency) to be honest in an environment of incomplete information. Theoretical studies generally aim to find the optimal contract or allocation that reduces corruption but fail to take account of the practical constraints actually faced by the principal. Practitioners often base their prescriptions on country experiences but lack an adequate analytical framework to guide their decisions.

The objective of this paper is to bridge this gap by developing a simple analytical framework that reflects realistic constraints faced by many developing and transition economies. We argue that the ineffectiveness of traditional incentives can explain the persistence of corruption and policy distortions in these countries. The traditional principal-agent literature relies on two types of incentive tools, "carrots," such as premiums for good performance, and "sticks" or penalties. More specifically, the literature suggests that corruption can be eliminated by increasing penalties, raising the probability of conviction, or by paying informational rents or efficiency wages (Mookherjee and Png, 1995; Basu and others, 1992;

\footnotetext{
${ }^{2}$ One consequence of rent seeking is that productive resources are diverted toward inappropriate activities, resulting in a misallocation of resources in the economy. For instance, agents may have higher incentives to allocate productive resources to rent seeking rather than to production activities (Chakraborty and Dabla-Norris, 2005), and government officials may endogenously increase the amount of red tape in order to extract more rents (Banerjee, 1997).

${ }^{3}$ In this paper, we use the terms corruption and rent seeking interchangeably, while acknowledging that the latter is more general than the former.
} 
Besley and McLaren, 1993). However, we argue that these solutions assume away the problems encountered in many parts of the world.

Attempts to utilize the "stick" strategy are frequently ineffective in many developing and transition countries. For instance, the political will or capacity to engage in monitoring and implement appropriate strategies may be lacking, or the legal and financial institutions, such as the judiciary, police, and financial auditors, required to enforce and enhance accountability in the public sector are weak (Rauch and Evans, 2000). Efficient legal and financial systems rely on a functioning enforcement mechanism, and the ability to delegate investigation and reviews to a trustworthy audit and legal machinery. In many developing and transition economies, in particular those characterized by systemic corruption, the institutional framework lacks credibility and is itself plagued by problems of corruption, so conventional mechanisms to control corruption, such as audits and legislative reviews, may be insufficient. ${ }^{4}$ Moreover, collusion, organizational deficiencies, abuse, and lack of responsiveness to citizens' needs cannot easily be detected and rectified even with the best of supervision. Therefore, when institutions are weak, the government's potential role as auditor and supervisor is even more constrained. Moreover, if the "stick" strategy is of little value in such situations, using the "carrot" strategy may not be feasible in practice as well, because in many of these countries official wages are often bounded and cannot be state-dependent, or information premiums are not conceivable. ${ }^{5}$

If traditional incentives are not effective, what can be done? Observing the persistence and stability of rent capture systems in many developing and transition countries, which have resisted considerable reform attempts, the paper argues that this reflects a stable equilibrium, resting on a social consensus between the different stakeholders. Our working hypothesis is that such a stable equilibrium, in turn, reflects the existence of multiple constraints that are binding simultaneously. As a result, relying on standard incentive tools to relax a single constraint at a time may neither be feasible, nor effective. In this environment, we argue that traditionally "external" factors (to direct public sector management, tools generally considered as decision variables in principal-agent models), especially enhanced transparency, can play an important role.

The distortions characteristic of many developing countries (e.g. rent seeking, corruption, procedural ineffectiveness) can frequently be traced to imperfections in political markets that

\footnotetext{
${ }^{4}$ The significant interrelationship between legal ineffectiveness and corruption suggests that strong forces tend to perpetuate corruption. For example, Damania and others (2004) show that, in politically unstable regimes, the institutions necessary to monitor and enforce compliance with regulations are weak, which, in turn, increases incentives for rent-seeking behavior, resulting in a higher level of noncompliance with existing regulations.

${ }^{5}$ For instance, Di Tella and Schargodsky (2002) argue that when control mechanisms are too weak or too strong, wages do not have any impact on corruption.
} 
are greater in some countries than in others (IMF, 2005). Incomplete information is at the heart of most theories of the breakdown of political markets. For instance, since uninformed voters cannot easily identify the effect of rent seeking on their welfare, politicians may have greater scope to extract rents (Keefer and Khemani, 2005). More specifically, the lack of transparency in rules, laws, and processes, and of effective institutional controls, are often advanced as contributing factors leading to corruption, and empirical evidence suggests that this may indeed be the case. Recanatini and others (2005) find that maintaining open and transparent procedures, including publicly announced budget and personnel decisions, is associated with lower corruption in public agencies. Using survey data on Bolivia, Kaufmann and others (2002) show that transparency has a larger effect on the quality of service delivery and corruption than the more traditional type of public sector management variables.

This paper examines the different channels through which transparency can contribute to reducing rent capture and increasing public output, in a situation where traditional incentives fail. We adopt an inductive analytical approach, by developing a coherent theory out of extensive theoretical and empirical evidence related to different strands of literature, including economic analysis of corruption, principal-agent theory, as well as sociological studies. Specifically, we develop a stylized model that draws upon a large body of theoretical and empirical work on corruption and reflects some realistic constraints faced by governments in developing and transition economies. We then summarize existing empirical evidence and country case studies to illustrate the effect of transparency on our model's constraints.

We argue that greater fiscal transparency and increased public access to information can allow for an insider-driven, "owned" mutation to better social outcomes. This argument is in line with recent initiatives by international financial institutions (IFIs) to enhance fiscal transparency across their member countries. For instance, IMF-supported programs frequently include measures designed to address institutional weaknesses, reduce opportunities for corruption and other forms of rent seeking, and promote good governance more generally (IMF, 2003). ${ }^{6}$ More generally, the IMF's involvement is aimed at increasing the transparency of government activities, the effectiveness of public resource management, and the stability and transparency of the environment in which the public sector operates. ${ }^{7}$

${ }^{6}$ Examples of such conditionality in IMF-supported programs include steps to strengthen revenue and customs administration (e.g. Bolivia and Armenia) and expenditure management (e.g. Azerbaijan and Côte d'Ivoire). In some instances, such as in Cambodia and Kenya, programs have had to address corruption that have important macroeconomic implications (IMF 2003).

${ }^{7}$ The Fund's Code of Good Practices on Fiscal Transparency and regular assessments of fiscal management practices through Reports on the Observance of Standards and Codes (ROSCs) rest on the following general principles of fiscal transparency: clarity of roles and responsibilities; public availability of information; open budget preparation, execution, and reporting; and assurances of integrity. 
The paper is organized as follows. Section II presents a simple model of public production and rent seeking, and outlines the various constraints faced in some developing and transition countries. Section III presents the theoretical results and explains the economic rationale behind our assumption that the constraints may be simultaneously binding. In Section IV, we explain how transparency can relax the different constraints at stake. Section V concludes.

\section{A STYLized Model}

We construct a simple model where a benevolent principal representing the population or citizen aims to optimize the public output, which is produced by a representative public agent. ${ }^{8}$ One can also think of this relationship in terms of the legislature, or other governing body employing the agent, such as a line ministry or planning bureaucracy, to identify needs for expenditures, and then accordingly allocate funds, the disbursement of which is overseen by the agent.

The public agency can exert effort either to produce the public output $\left(e_{1}\right)$, or engage in selfinterested rent seeking (including corrupt) activities $\left(e_{2}\right)$, with total effort normalized to one $\left(e_{1}+e_{2}=1\right) .{ }^{9}$ Rent seeking entails a "sunk" cost $0 \leq \alpha \leq 1$, so that the total rent appropriated by the agent is equal to $R=(1-\alpha) e_{2}$. The assumption of a sunk cost to rent seeking captures the idea that rent seeking entails waste, resources spent on competition over possible rents (Buchanan et al,1980) or other directly unproductive, profit-seeking activities (Bhagwati 1980).

The public output produced depends on the agent's effort along with other factors, such as productivity, cost of provision of public services, denoted by $\theta$. As in Sarte (2001), $\theta$ can be regarded as capturing some private information that the agent has with respect to the technology used to produce public goods. ${ }^{10}$ For instance, the average cost associated with the

\footnotetext{
${ }^{8}$ We do not differentiate between outputs, outcomes, and results, and use these terms interchangeably.
}

${ }^{9}$ Such rent seeking is not exclusive to the government sector or to developing countries. Dickens and others (1989) provide some examples of employee crimes in the United States, showing that rent seeking by workers can generate large financial losses in many industries. They report that as much as 80 percent of shipping losses in the freight and airport cargohandling industries arises from employee theft; 30 percent of retail employees steal merchandise from the workplace or misuse discount privileges; 27 percent of hospital employees steal hospital supplies; and 9 percent of workers in manufacturing falsify their time cards.

${ }^{10}$ Niskanen (1991) notes that the primary advantage of a bureau is that it has much better information about the costs of supplying the public service than does the principal. More 
provision of government services can be random and its realization costlessly observable only to the agent; however, it is not directly observable by the principal, who only knows its distribution. For simplicity, we consider an additive productive function and assume that public output, $x$, where $x=e_{1}+\theta$, is publicly observable at no cost. However, $\theta, e_{1}$, and hence, $e_{2}$ and $R$, are the agent's private information.

The agent is paid an official wage $w$. In addition, we assume that he derives some "internal" utility, denoted by $\varepsilon$, from providing the public output. This assumption reflects the fact that agents, and in particular bureaucrats, are not exclusively materially self-interested. They can also be motivated by public service motivation (Perry and Wise, 1990), intrinsic motivation for the job performed (Frey, 1997), and social motivation like enhanced prestige and power from the production of the public good (see Paul and Robinson, 2005, on these issues).

The principal knows that the production process may be subject to rent seeking, and can engage in costly monitoring. We denote as $C$ the cost of controls implemented by the principal. For simplicity, we regard control costs as being proportional to the amount of effort expended by the principal. The expected penalty inflicted on the agent when caught, $\Pi$, is assumed to be a function of the principal's control effort and the size of the captured rent. This penalty can be viewed as fines, the probability of loosing future employment opportunities, loss of promotion, or imprisonment.

Assumption 1: The penalty function is of the form $\Pi(C, R)=C R^{2}=C\left[(1-\alpha) e_{2}\right]^{2}$, with $\Pi(0, R)=0 ; \Pi(C, 0)=0 ; \frac{\partial \Pi}{\partial C}=\left[(1-\alpha) e_{2}\right]^{2}>0 ; \frac{\partial \Pi}{\partial e_{2}}=2 C(1-\alpha)^{2} e_{2}>0 ;$ and $\frac{\partial^{2} \Pi}{\partial e_{2}^{2}}=2 C(1-\alpha)^{2}>0$

This formulation implies that the expected penalty is zero in the absence of rent seeking and if the principal is not investigating corruption; and it is increasing in the principal's control effort and in the size of the rent captured by the agent. Moreover, the penalty function exhibits less tolerance for higher levels of corruption. ${ }^{11}$

generally, we can think of the agent as using his powers of information collection and expenditure oversight to either manipulate the principal or to extract rents for himself. For example, in preparing an itemized budget for submission to the principal, he can spend more effort identifying attractive infrastructure projects from which he can extract rents relative to identifying pressing needs for social expenditures than the principal would in his place.

${ }^{11}$ A general functional form that satisfies these desired properties is $\Pi(C, R)=C^{\phi} R^{\varphi}$ for any $\phi>0$ and $\varphi>1$. 
For the sake of simplicity, we assume that the agent's expected utility is an additive function of his wage, internal motivation, and rents appropriated, minus the expected penalty:

$$
U=w+\varepsilon\left(e_{1}+\theta\right)+(1-\alpha) e_{2}-\Pi(C, R)
$$

The principal's objective is to maximize the public outcome, net of wages, and control costs: ${ }^{12}$

$$
E(X)=e_{1}+\theta-w-C
$$

Two remarks are worth making at this stage. First, rent capture is socially inefficient. Other things being equal, the loss incurred by society when $e_{1}<1$ is equal to $1-e_{1}=e_{2}$, while the benefit to the agent of exerting effort less than 1 to producing the public output equals $(1-\alpha) e_{2}-\Pi(C, R)-\varepsilon\left(1-e_{1}\right)$. The net social loss is thus equal to $(\alpha+\varepsilon) e_{2}+\Pi(C, R)$, which is always positive (it is zero at $e_{1}=1$ ). Second, while the principal's objective function is increasing in $e_{1}$, the effect of an increase in $e_{1}$ on the agent's utility is ambiguous. ${ }^{13}$ As long as it is positive, the principal's and the agent's interests are aligned, and the agent exerts effort to produce the public output. However, an agency problem arises when $\left(\partial U / \partial e_{1}\right)<0$, in which case the agent will increase his effort devoted to rent seeking activities.

In a standard principal-agent model, the principal acts as a Stackleberg leader offering a contract that maximizes his objective function, taking into account the agent's reaction function. The contract must also fulfill a participation constraint for it to be accepted by the agent. In this framework, the agent's participation constraint $(P C)$ takes account of the implicit rent accruing to the agent, and may be written as

$$
U \geq u^{*}
$$

where $u^{*}$ represents the agent's reservation utility. Note that if official wages are bounded, the agent's utility could encompass some illegal, but socially accepted rent capture. The principal would thus opt for "capitulation wages," i.e. wages below reservation wages, that

${ }^{12}$ Note that, as we have assumed total effort to be normalized to one, we abstract from "disutility of work" in the agent's utility function.

${ }^{13}$ Note that the derivative of (1) with respect to $e_{1}, \partial U / \partial e_{1}=\varepsilon-(1-\alpha)+2 C(1-\alpha)^{2}\left(1-e_{1}\right)$, can either be positive or negative depending on the underlying parameter values. 
attract only the dishonest agents, rather than raise wages to the high levels required to deter corruption (Besley and McLaren, 1993; Dabla-Norris, 2002).

We assume the public agency is also subject to what we call a "minimum eequirement constraint" $(M R C)$.

Assumption 2: The relationship between the public agency and the principal is regulated through implicit social consensus, such that the agency is required to produce at least a certain amount of the public good.

Our $M R C$ attempts to capture the idea that it is socially tolerated that the public agent captures some rents for its network, but only if it provides at least a certain minimum level of public good for the whole population. This assumption constitutes a crucial postulate of our paper. It reflects the fact that in close-knit societies, corrupt behavior on the part of public officials is frequently tolerated or sanctioned by the population. Sociological studies of corruption provide several explanations for this tolerance. In many of these countries, society is organized along patronage networks, where individuals benefit from various types of "redistribution" (direct transfers, protection in hard times, nepotism, etc.) from their patrons. These networks function on the basis of a series of reciprocal "gift exchanges" between patrons and clients (Mauss, 1923) and corruption networks, ranging from petty to high-level corruption, are intertwined (see Blundo 2001 for the example of public procurement in Senegal). Corruption then becomes institutionalized and structural, such that the state is held hostage by various social and political segments (Bako-Arifari 2001). As a result, day-to-day corruption becomes legitimized by the social and economic environment within which individual agents operate (Blundo and de Sardan, 2001). ${ }^{14}$

Another explanation for the tolerance of corruption in some societies lies in the nature of foreign aid. For instance, to the extent that the provision of the public good is partially financed by external donors, rent capture in public projects may be socially acceptable, because that money is viewed as "cold," not domestically owned and subject to accountability to the local population, as opposed to money "warmed" by social relationships (Poncelet and others, 2005). ${ }^{15}$ As a result of these factors, corruption maybe socially accepted by the population - but only up to a point, since there must be an equilibrium between the different networks in place. This is particularly the case where the central government is weak and made up of a coalition of polarized factions (Easterly, 2001). Therefore, in

\footnotetext{
${ }^{14}$ A study of corruption in Senegalese hospitals states that rent extraction practices are tolerated and legitimized by society (see http://www.idrc.ca/en/ev-87470-201-1DO_TOPIC.html ). Another explanation lies in the social importance of "big men," whose power and wealth is a factor of pride for their networks (Medard, 1992).

${ }^{15}$ Martens and others (2002) note that foreign aid funds are subject to a "broken feedback loop" which reduces accountability.
} 
compliance with a social consensus negotiated with the population, the agent implicitly accepts to produce at least a certain level of public outcome, which we call $Y$. The $M R C$ is given by:

$$
E(x)=e_{1}+\theta \geq Y
$$

In exchange for producing the public good, the population agrees that the agent should receive some minimum utility. ${ }^{16}$ This is captured in $P C$, the participation constraint. We view the two minimum requirements, $u^{*}$ and $Y$, as the outcomes of a negotiation process between the agent and the population. While we do not explicitly model this process, their respective levels can be viewed as depending on the bargaining power of each actor. Note also that, as they are implicitly negotiated, these requirements could be context-specific. For instance, in the event of an observable adverse productivity or other exogenous shocks (presumably a low $\theta$, for instance following a drought) both parties may be more tolerant and accept a lower $Y$ and $u^{*}$.

Finally, in addition to the participation constraint, we assume that the principal also has to satisfy a budget or cash constraint, which states that the expenditures devolved to pay the agent and exert controls cannot be higher than a cash ceiling $B$ :

$$
w+C \leq B
$$

Standard principal-agent models rely on incentive compatibility $(I C)$ constraints, which state that the agent's expected utility when behaving honestly should be greater or equal to what he may expect if he shirks. ${ }^{17}$ Introducing $I C s$ in our framework would require us to specify output-dependent transfers, and thus the distribution of $\theta$, which would complicate the model. We do not follow this approach for two reasons. First, the results from this approach, the traditional efficiency and rent extraction trade-off, are already well-known in the literature (for example, see Laffont and Martimort, 2002). More important, this paper is based on the premise that many of the traditional incentive tools considered in the literature may not be enforceable in the context of developing and transition economies.

Empirical evidence suggests that rent seeking is reduced when firms pay higher wages, for example, see Cappelli and Chauvin (1991), and Goldsmith and others, (2000), notably

\footnotetext{
${ }^{16}$ In a similar vein, Akerlof (1982) examines the idea that labor contracts are partial gift exchanges. In his model, workers' efforts depend on the work norms of their group, so that the firm can succeed in raising group work norms and average effort by paying workers a gift of wages in excess of the minimum required.

${ }^{17}$ The Revelation Principle asserts that the principal cannot do better than offering an incentive-compatible contract.
} 
because more competitive salaries might reduce incentives to take bribes or engage in other types of rent seeking behavior, given the reduction in the marginal utility of income and increase in the disutility of being fired if one is caught engaging in corrupt activity. However, in the absence of adequate controls, very large increases in wages would be required to eradicate corruption solely by raising wages, which could be incompatible with a tight budget constraint. ${ }^{18}$ Moreover, the principal may have little ability to relate the wage to observed outcomes if official wages are bounded and if reliable information on performance is lacking. As a result, neither pay-for-performance nor efficiency wages are possible in this situation. The principal would thus lack the usual "carrot" incentive, and as a result may resort to offering capitulation wages.

Moreover, the principal may also lack an adequate "stick" incentive, as ineffective judicial systems and weaknesses in the rule of law imply that actual penalties for civil servants are very low or ineffective in many developing countries (Moussa, 2004; Lienert 2003). In reality, one might also expect oversight and monitoring to be more difficult in economies where rent seeking is pervasive (Kaufman et al, 2002; IMF, 2005). In essence, substantial resources would have to be spent to monitor a bureaucracy that is deeply entrenched in a culture of corruption. By contrast, monitoring might be more easily carried out when there already exists little tolerance for rent seeking. Under this interpretation, the increase in $C$ required to reduce corruption would directly depend on the degree to which a tradition of corruption is well established, and simply raising wages may not be sufficient to eliminate or even reduce rent seeking behavior. ${ }^{19}$

Finally, further constraints, while not explicitly modeled for, may also limit the principal's means of action, such as those arising from externally imposed policy conditionality, and limits on the country's ability to incur debt or increase public sector wages under IMF programs. The consequence of these particular constraints is that it may no longer be feasible to fulfill $I C$ s as in standard principal-agent models. ${ }^{20}$

${ }^{18}$ High wages may be necessary not only to eradicate corruption, but also to give appropriate incentives for performance. For instance, a study on Indonesia shows that it would require multiples of current pay levels to get doctors to live in West Papua (Chomitz and others, 1998).

${ }^{19}$ In general, the higher the costs of investigating and deterring corruption, the more corruption we would expect to see in the economy. To see this, consider a cost parameter $\lambda$ that multiplies a general cost of control function of the form $\Omega(C)$, where $\Omega$ ' $(C)>0, \Omega$ ' $(C) \geq$ $0, \Omega(0)=0$, and $\Omega^{\prime}(0)=0$, such that the cost of investigating corruption equals $\lambda \Omega(C)$. An increase in $\lambda$, raises the marginal cost of the principal's control effort, for any given level of investigation/monitoring effort chosen by the principal. This leads to a lower level of control effort expended, and consequently a higher level of corruption in the economy.

${ }^{20}$ Note that if the principal wanted to induce the agent to devote all his effort to the production of the public output, by solely using controls and no performance premiums, the 
For these reasons, we do not follow the traditional approach of defining the optimal contract using the revelation principle. Instead, we describe the results of our model in light of the constraints outlined above. In our model, the only incentive tools available to the principal are limited controls and, in an even more limited sense, basic wages. Therefore, the agent's problem is to choose his level of effort - and thus corruption - so as to maximize his utility, given the policy parameters (the cost of control and wages), subject to the minimum requirement constraint:

$$
\begin{gathered}
\max _{e_{2}} E(U)=w+\varepsilon\left(1-e_{2}+\theta\right)+(1-\alpha) e_{2}-C\left[(1-\alpha) e_{2}\right]^{2} \\
\text { s.t. } 1-e_{2}+\theta \geq Y
\end{gathered}
$$

The principal's problem is to maximize public output net of wages and control costs, subject to the agent's reaction function above, plus the participation and the budget constraints:

s.t.

$$
\begin{gathered}
\max _{w, C} E(X)=1-e_{2}+\theta-w-C \\
w+\varepsilon\left(1-e_{2}+\theta\right)+(1-\alpha) e_{2}-\Pi(C, R) \geq u^{*} \\
w+C \leq B
\end{gathered}
$$

\section{RESULTS AND IMPLICATIONS}

\section{A. Theoretical Results}

We distinguish between different regimes that can be enforced by the principal depending upon the level of control he applies and the wages offered (detailed proofs are provided in the Appendix). The optimality of these possible contracts depends on underlying parameter values and whether or not the constraints are slack or binding (i.e. hold with equality).

In particular, one crucial question is whether $M R C$ is binding or not. One interpretation for the $M R C$ stems from the idea that public agents may be subject to two different accountability systems. On the one hand, they are governed by the formal rules and institutions associated with the civil service. In our model, these are captured by the controls

$I C$ would be such that: $w+\varepsilon(1+\theta) \geq w+\varepsilon\left(1-e_{2}+\theta\right)+(1-\alpha) e_{2}-C\left[(1-\alpha) e_{2}\right]^{2}$. Controls would have to satisfy the condition $C \geq\left[(1-\alpha-\varepsilon) /(1-\alpha)^{2} e_{2}\right]$. As $\lim _{e_{2} \rightarrow 0}\left[(1-\alpha-\varepsilon) /(1-\alpha)^{2} e_{2}\right]=\infty$, the principal would need to exert an infinite control effort to prevent any rent seeking. 
and incentive schemes implemented by the principal. On the other, a series of informal rules and institutions coexist in all organizations, such as work norms and corporate culture. In some developing countries, these informal or indigenous rules may be much more important than formal ones. As Dia (1996: 1) notes, "these formal institutions may be at odds with societal behavior, expectations, and incentive systems and therefore face a crisis of legitimacy and enforcement. Their ineffectiveness is compounded by the absence of the rule of law as a third-party enforcement mechanism, engendering a climate in which enforcing formal contracts and procedures becomes costly, often prohibitively so, and sanctions for deviant behavior are devoid of credibility. By contrast, indigenous institutions anchored in local culture and values can count on the sound pillars of legitimacy, accountability, and selfenforcement. They have a strong hold on people's commitment, dedication, and sense of identity." It is precisely this "traditional" accountability mechanism between the public agents and the population that the minimum requirement constraint, $M R C$, intends to capture.

Following this interpretation, when $M R C$ is slack, the agent's formal accountability system, i.e. with respect to the official civil service rules, is sufficient, and controls are a relevant decision parameter for the principal. Technically speaking, when the $M R C$ is slack, both the principal and agent face a real optimization problem: the principal sets the level of controls and wages in order to maximize public output, taking into account the agent's response to its own maximization problem. In this case, the more controls exerted by the principal, the less effort the agent dedicates to rent seeking activities. A binding $M R C$, however, implies that the agent's effective accountability is to the population, so that the level of output produced is determined only by the implicit social consensus. In such a situation, we show below that it is not profitable for the principal to exert any controls. The principal is thus left with no real policy instrument to control the agent.

In what follows, we present the main theoretical results predicted by our model, and then explain some policy implications.

Result 1: A regime where $M R C$ is slack can be enforced if $C>\frac{1-\alpha-\varepsilon}{2(1-\alpha)^{2}}$, and the agent chooses a level of rent capture such that $e_{2}^{*}=\frac{1-\alpha-\varepsilon}{2 C(1-\alpha)^{2}}$.

This result suggests that the principal can enforce a regime where $M R C$ is slack only by exerting high controls. The agent's optimal rent seeking effort, which equates the marginal benefit of rent seeking to its marginal cost, clearly depends on the principal's choice of control. ${ }^{21}$ Note that, given our assumptions, the derivatives of $e_{2}^{*}$ with respect to control costs

\footnotetext{
${ }^{21}$ Recall that an agency problem occurs only if $1 \geq \alpha+\varepsilon$, otherwise the agent's and principal's interests are aligned without control. Note also that when the principal exerts
} 
$C$, and to the agent's intrinsic utility from providing the public output $\varepsilon$, are unambiguously negative. However, the derivative with respect to the sunk cost to rent seeking $(\alpha)$ may be positive if $\varepsilon$ is small, and negative if $\varepsilon$ is large. For an initially low $\varepsilon$, the principal can increase the agent's effort dedicated to the production of the public good only by raising $C{ }^{22}$

The optimal levels of control and wages, however, can vary depending upon underlying parameter values and the tightness or slackness of other constraints.

Result 1.1: In a regime where $M R C$ and $P C$ are slack, $w^{*}=0$, and (i) if $B C$ is slack:

$$
\begin{aligned}
& C^{*}=\sqrt{\frac{1-\alpha-\varepsilon}{2(1-\alpha)^{2}}} \text { and expected output is } E(X)=1+\theta-\frac{\sqrt{2(1-\alpha-\varepsilon)}}{(1-\alpha)} \text {; (ii) if } B C \text { is binding: } \\
& C^{* *}<\sqrt{\frac{1-\alpha-\varepsilon}{2(1-\alpha)^{2}}} \text {, and } E(X)=1+\theta-\frac{1-\alpha-\varepsilon}{2 B(1-\alpha)^{2}}-B .
\end{aligned}
$$

Zero wages may seem like a surprising result, but can be viewed as an extreme case of a situation where the principal opts for capitulation wages because it would be too costly to provide agents with efficiency wages. However, in general, wages will be positive to help satisfy the participation constraint. Note also that the optimal level of controls is lower if the budget constraint is binding, which induces the agent into devoting more effort to rent capture. Hence, the principal's expected output will be lower.

As is shown in the appendix, the solution to the problem becomes more complicated if $P C$ is initially binding. Generally speaking, to receive political support and have a chance of being successfully implemented, reforms should leave its critical implementers with at least as much utility as before (Drazen 2000). In our model, this is rendered through the participation constraint. However, if $P C$ is initially binding, reforms associated with a reduction of rent capture are implementable only if the public agency can be compensated by an increased explicit utility. Specifically, we can show that

heavy controls, the agent does not engage in rent seeking $\left(\lim _{C \rightarrow \infty} e_{2}^{*}=0\right)$, while when control is very low and no other constraint interferes, he devotes his entire effort to rent seeking $\left(e_{2}^{*}=1\right)$.

${ }^{22}$ Note that if $\varepsilon$ were an endogenous variable, the principal could also increase the agent's effort devoted to producing the public good by raising $\varepsilon$, as long as $C>1-\alpha-\varepsilon$. 
Result 1.2: In a regime where $M R C$ is slack but $P C$ is binding, the principal determines wage and control cost such that $w^{*}+\varepsilon(1+\theta)+\frac{(1-\alpha-\varepsilon)^{2}}{4 C^{*}(1-\alpha)^{2}}=u^{*}$. The optimal level of wages and control depends on whether $B C$ is slack or binding: (i) if $B C$ is slack, control costs are $C^{* * * *}=\frac{\sqrt{(1-\alpha-\varepsilon)(1+\alpha+\varepsilon)}}{2(1-\alpha)}<C^{*}$ and expected output is $E(X)=(1+\theta)(1+\varepsilon)-u^{*}$; (ii) if $B C$ is binding, the principal should incur a still lower control cost, and expected output is $E(X)=1+\theta-\frac{1-\alpha-\varepsilon}{2\left(B-w^{*}\right)(1-\alpha)^{2}}-B$.

We observe that when more constraints are binding, the principal should exert lower controls. Furthermore, the lower the controls, the higher the extent of rent capture by the agent, and thus lower the expected output for the principal. However, recall that the optimal control level must be $C>\frac{1-\alpha-\varepsilon}{2(1-\alpha)^{2}}$ to enforce a regime where $M R C$ is slack. Depending on underlying parameter values, it may not be profitable to incur control costs - in which case the principal is left with the option of enforcing a regime where $M R C$ is binding.

Result 2: A regime where $M R C$ is binding is enforced if $C<\frac{1-\alpha-\varepsilon}{2(1-\alpha)^{2}(1+\theta-Y)}$, with $e_{2}^{*}=1+\theta-Y$. Optimal control effort is then $C^{*}=0$ and (i) if $P C$ is slack, $w^{*}=0$ and $E(X)=Y$; (ii) if $P C$ is binding, $w^{*}=u^{*}+Y(1-\alpha-\varepsilon)-(1-\alpha)(1+\theta)$, for $w^{*} \leq B$, and $E(X)=Y-w^{*}=Y(\alpha+\varepsilon)+(1-\alpha)(1+\theta)-u^{*}$.

Result 2 suggests that in a regime where $M R C$ is binding, it is not profitable for the principal to exert any controls (i.e. optimal level of control is $C=0$ ). Depending on whether $P C$ is binding, the principal will have to pay positive wages, otherwise the agent is paid mostly through rent capture. One implication of this result is that if the minimum requirement $Y$ increases, the agent's effort dedicated to the production of the public output will also increase. However $P C$ must be satisfied, which may require raising wages or a higher internal motivation.

Due to the endogenity of $C$ and $e_{2}$ when $M R C$ is slack, comparing the two regimes and eliciting the optimal contract is not straightforward. One would need to determine whether it is feasible to implement a regime where $M R C$ is slack, which, in turn, depends on whether the budget constraint allows for some positive control, such that $C>\left[(1-\alpha-\varepsilon) / 2(1-\alpha)^{2}\right]$. Second, whether or not it is efficient to do that would depend upon underlying parameter 
values. It may, however, be the case that it is less costly not to incur any control cost, and enforce a regime where $M R C$ is binding.

\section{B. Analysis and Implications}

Principal-agent theory suggests that constraints are substitutes for performance incentives (Holmström and Milgrom, 1991). The results outlined in the previous section suggest that as long as $M R C$ is binding, the principal should pay the lowest wage that satisfies the agent's participation constraint - thereby, ruling out any monetary incentives for performance. More important, he should not incur any control cost, thus allowing for possibly large-scale rent capture, which is consistent with the results obtained in other models on corruption (DablaNorris, 2002; Acemoglu and Verdier, 2000) and may reflect the actual situation in many developing countries. ${ }^{23}$ Nevertheless, due to our $M R C$ assumption, the extent of rent capture will be mitigated by a "ceiling" of what is socially acceptable as part of the implicit consensus between the agent and the population.

In practice, $M R C$ may be binding in some developing countries, in particular those characterized by a divergence between formal and informal rules and institutions, as is the case in many Sub-Saharan African countries (Dia, 1996). In these countries, it is often the case that adherence to civil service rules is weak and formal controls are ineffective (notably because the legal system is not credible), so that accountability to official rules is concomitantly weak. At the same time, informal rules, such as those captured by the social consensus, are probably respected. In such a situation, the only effective accountability mechanism is an implicit consensus between the agent and the population.

The above results also suggest that the principal can hope to get a better public outcome (over the minimum requirement) only if $M R C$ is slack. This is the case when controls are sufficiently high. ${ }^{24}$ Other things being equal, increasing $C$ will align the agent's interest with that of the principal, making it optimal for the agent to decrease rent seeking. However, the principal will still need to respect the agent's participation constraint. This implies that reforms which desire to reduce corruption will necessitate raising concomitantly the agent's utility, provided that the budget constraint allows for it. The low level of public sector wages in developing and transition countries is often posited as a cause of corruption. In cross-

${ }^{23}$ Acemoglu and Verdier (2000), for instance, note that corruption arises as part of an optimal allocation of government activities when there are incomplete contracts and incentive problems.

${ }^{24}$ Note that increasing controls may take different forms. Public expenditure management encompasses different types of control, including internal and external, ex ante and ex post, centralized and decentralized, compliance and performance controls. The design of the control function is an important question which is not dealt with in this paper (see Leruth and Paul [forthcoming] on that issue). 
country regressions, Van Rijckeghem and Weder (2001) find evidence of a statistically significant relationship between relative civil service pay and corruption. However, Rauch and Evans (2000) find that the level and change in bureaucratic compensation relative to the private sector are not statistically significant determinants of different measures of bureaucratic performance. Similarly, Di Tella and Schargrodsky (2002) argue that when control mechanisms are weak, wages do not have any impact on corruption.

The persistence of corruption in developing and transition countries could also reflect the fact that the constraints described in our model are binding simultaneously. This is indeed suggested by the literature, and seems to reflect the reality of many developing and transition countries. First, the minimum requirement constraint will be binding unless the agent has sufficient incentives to exert a high productive effort, either due to internal motivation to perform or to the risk of being punished if caught engaging in corrupt activities. As we have already argued, both these types of incentives may be lacking in many developing countries. Second, the participation constraint might be binding, if the principal lacks the ability to offer sufficient incentives to induce an efficient level of effort. Our model predicts that when $M R C$ is binding, it is inefficient to exert any controls, so that the principal should offer the lowest wage that fulfills the $P C{ }^{25}$ Moreover, it can also be the case that due to repeated interactions, the population and the public agent reach a social consensus, setting $Y$ and $u^{*}$ such that $M R C$ and $P C$ are binding simultaneously. Third, the government's budget constraint can be very tight in many developing and transition countries, due to the inefficiency of fiscal administrations, IFI conditionality which places limits on the wage bill, and numerous competing needs in terms of public expenditure.

If $B C$ was slack, increasing the public outcome could be achieved by an appropriate mix of controls to reduce rent capture and wages to satisfy the participation constraint. Technically speaking, this would equate to introducing some type of incentive compatibility constraint. However, as discussed above, in reality the existence of a binding budget constraint, and possibly other constraints not explicitly accounted for in our framework (for example, due to the local political processes, or external pressures from IFIs and donors), prevent the provision of adequate incentives in many cases. Furthermore, when $M R C$ is binding, the only way by which the principal can get a higher public output is by raising the minimum requirement level $Y$, which is not a direct policy instrument, but considered exogenous in our model. The principal's problem therefore seems unsolvable. In the next section, we examine alternative ways to get the equilibrium to move in a direction favorable to the public interest when traditional incentives are unavailable.

\footnotetext{
${ }^{25}$ Note, however, that in reality one generally observes some positive controls. This could render two cases: either the principal does not choose the optimal level of control when $M R C$ is binding due to political or externally imposed constraints, or $M R C$ is binding at the agent's optimal level of rent capture, i.e. $e_{2}^{*}=1$ (corner solution).
} 


\section{The Role OF Transparency}

In this paper, we have presented the problem of rent seeking as an agency problem, arising from diverging interests and asymmetric information between a public agency and its principal (representing the public interest). We have argued that the principal cannot disentangle between the effort dedicated by the agent to the production of the public good, and some external factors, unless it exerts costly controls. In this section, we examine the role of transparency in reducing the agency problem presented above. While we do not explicitly model the effect of transparency in our framework, we illustrate different ways through which the provision, diffusion and use of information, both within and outside the agency, may contribute to reduced rent capture and higher public output. We highlight the role of transparency on two of the model's constraints, namely the minimum requirement constraint, $M R C$, and the participation constraint, $P C$. We also examine the second-order effect of transparency on the budget constraint, $\mathrm{BC}$, and other indirect political and social effects. In line with our analytical approach, we present some arguments and justify them with supporting empirical evidence.

The literature suggests various ways in which greater transparency may reduce the information asymmetry between principals and agents, thereby improving the public outcome. On the theoretical side, Holmström (1979) has shown that in moral hazard principal-agent problems, more information about the agent makes him more accountable to the principal. Recent empirical evidence suggests that the lack of transparency and of effective institutional controls are the main factors leading to corruption in areas of spending decisions such as investment projects and procurement spending. For instance, Broadman and Recanatini (2002) argue that a well-established system of market institutions, including clear and transparent rules and fully functioning checks and balances, reduces opportunities for rent seeking and hence incentives for corruption. In cross-country regressions, Brunetti and Weder (2003) and Ahrend (2002) show that a free press may be a powerful control on corruption, and that the direction of causation runs from higher press freedom to lower corruption.

Note that it may be the case that corruption and transparency are jointly determined. For instance, poor transparency may lead to a higher level of corruption as the public official has greater discretionary power. On the other hand, widespread corruption may lead to poor transparency, as corrupt agents, reluctant to be exposed, attempt to weaken information flows within the public agency. Kaufman and others (2002), however, find that even controlling for the potential endogenity between the two, greater transparency of decisions in personnel, budget management, and service delivery can have a significant negative effect on corruption.

\section{A. Effect on the Minimum Requirement Constraint}

Increased transparency can have an impact on the minimum requirement constraint by raising the minimum public output required from the agent. From our model's perspective, we can view transparency as improving the observability of $\theta$ and $e_{2}$ by the public. It is now widely 
recognized that increasing citizens' voice can enhance government accountability, and 'for the expanded 'voice' strategy to be effective, it is essential to improve transparency of government action" (World Bank 2000, p. 91). For instance, raising public awareness or access to information on the working of public programs could make it easier for citizens to demand certain standards and monitor abuses by public officials. This, in turn, would compel the agent to reduce rent capture and increase the effort dedicated to the production of the public output. In our model, as long as $M R C$ is binding, this would be the most effective way to improve the principal's situation.

In a series of empirical studies on the importance of transparency for public funds, Reinikka and Svensson $(2004,2005)$ argue that corruption can be effectively tackled only when the reform of the political process and the restructuring of the regulatory systems are complemented by a systematic effort to increase the citizens' ability to monitor and challenge abuses of the system, and to inform citizens about their rights and entitlements. In practice, the IMF's Code on Good Practices on Fiscal Transparency, and the adherence to standards in the form of country ROSCs (Reviews of Standards and Codes), envisage a similar role for fiscal transparency. ${ }^{26}$ Petrie (2003) notes too that in addition to providing a means for governments to assess and build their capacity for fiscal management, "it is also anticipated that fiscal transparency may, over time, enhance oversight by civil society and the public of the conduct of fiscal management."

The effect of transparency in raising the "minimum requirement" in our model could be due, for instance, to increased bargaining power in the hands of the population when negotiating the social consensus. Recent empirical evidence indeed suggests that transparency can play such a determining role. Reinnika and Svensson (2005) evaluate the effects of increased public access to information as a tool to reduce corruption and capture of public funds in Uganda. They find that the extent of corruption appears to have less to do with conventional audit and supervision mechanisms, and more to do with the citizen's opportunity to voice their claims for the funds, and their relative bargaining positions. At the same time, greater transparency of action may reduce the agent's will to engage in rent seeking activities - for instance, it could serve to reduce the pressure exerted by civil servants' family and clientele networks to capture rents in order to redistribute them.

\section{B. Effect on the Participation Constraint}

Transparency may help relax the participation constraint in several ways. For instance, more transparent merit-based procedures for hiring and internal promotion may increase the utility derived by the agent from internal motivation $(\varepsilon)$. Other things equal, this could allow for

${ }^{26}$ Fiscal transparency "should lead to a better informed public debate about the design and results of fiscal policy, make governments more accountable for their implementation of fiscal policy, and thereby strengthen credibility and public understanding of macroeconomic policies and choices" (IMF Survey 1998, p. 122). 
lower rent capture, while satisfying the participation constraint. Moynihan and Pandey (2005) show that creating an environment which allows employees to feel that they are contributing to the public good increases public service motivation. In addition, there is some evidence to suggest that nonmonetary incentives may actually serve to reduce corruption. In a cross-country study, Rauch and Evans (2000) find that meritocratic recruitment and promotion are statistically significant determinants of good bureaucratic performance, while the effect of competitive salaries on bureaucratic quality is unclear. Using survey-level data, Recanatini et al (2005) find that basing personnel decisions on criteria of merit and professional competence are associated with lower corruption in public agencies.

Transparency, in the form of better quality and timely provision of fiscal data and limits on the use of extrabudgetary procedures, can facilitate the control function and increase penalties for rent extraction. Practitioners frequently relate lack of transparency and accountability to poor enforceability of existing rules (Campos and Pradhan, 1996), which undermines the control function and allows for corruption (Moussa, 2004; Lienert, 2003). In our model, this would translate into a higher $C$, and thus a higher expected penalty. As a result, when $M R C$ is slack, the effort dedicated to rent seeking $\left(e_{2}^{*}\right)$ would accordingly be lower.

Finally, our model captures the idea that rent-seeking activities are socially costly, because of the sunk cost $\alpha$ associated with concealing them. Shleifer and Vishny (1993) argue that the illegality of corruption and the attendant need for secrecy make it much more distortionary and costly (than taxation), since it induces a substitution into goods on which bribes can be more easily collected without detection. Transparency may act in opposing ways on $\alpha$. On the one hand, one could argue that greater transparency increases the cost of concealing corruption, and thus has a negative effect on $P C$. Alternatively, one could also argue that transparency, by making rules more clear and secure, could help improve the "industrial organization" of rent seeking. However, to the extent that transparency reduces the cost of enforcement, on balance, its effect would be to relax $P C$ and help improve the principal's situation.

\section{Effect on the Budget Constraint}

Reducing $e_{2}$ through increased controls is costly, and keeping an initially binding $P C$ satisfied would require increasing wages, hence, the importance of relaxing $B C$. As discussed above, greater transparency can ease the government's control function; conversely, at a given level of effectiveness, it reduces the cost of control and thus relaxes the budget constraint. More generally, relaxing the budget constraint calls for looking for fiscal space, i.e. in its broadest sense, "the availability of budgetary room that allows a government to provide resources for a desired purpose without any prejudice to sustainability of a government's financial position" (Heller, 2005).

There are different ways in which a government can create fiscal space: tax policy measures and strengthening of tax administration, reprioritization of expenditures, government borrowing, and foreign aid. Transparency can have important second-order effects on the 
budget constraint. It can improve the efficiency of the tax administration and lower discretion and interference in revenue forecasting and collections. Danninger and others (2005) find that a high degree of transparency in revenue forecasting, as measured by publicly available information on revenue forecasts and participation of nongovernment agencies in the forecasting process, reduces government interference and governance-related problems in revenue collection. A higher degree of transparency in budget management can make it easier to conduct intersectoral comparisons, thereby facilitating the elaboration of mediumterm expenditure frameworks and the prioritization of expenditure. Moreover, it can improve lenders' and donors' trust, thus improving loan opportunities and increasing aid flows, and possibly convince donors to rely more on efficient channels for managing aid, such as budget support (Leruth and Paul, 2006).

\section{Other Effects of Transparency}

In addition to the effects on our model's constraints outlined above, transparency can have other indirect, but important effects. At the political level, Robinson and Verdier (2002) argue that inefficient practices such as clientelism and gift exchanges arise from politicians' inability to commit to more efficient policies. In a similar vein, Keefer and Vlaicu (2004) and Keefer (2005) note that the inability of political competitors in young democracies to make credible promises to citizens, explains why younger democracies are more corrupt, and exhibit weaker rule of law and lower levels of bureaucratic quality. Transparency of fiscal actions can enhance politicians' ability to commit to development-oriented policies, thereby reducing incentives for inefficient practices. In the longer term, transparency might help reduce social polarization, which is a determinant of the incentives of government to provide public services (Easterly, 2001). For example, one study of Bolivia emphasizes the importance of transparency in the depoliticization process and in facilitating political consensus building (World Bank, 2000).

Davis (2004) notes that the two concomitant drivers of reduced corruption in public service delivery are a shift in the accountability networks of service providers, and a change in the work environment that increases the moral cost of misconduct. The first relates to the issue of beneficiaries' voice and civil servant accountability. The latter relates to the internal motivation of a bureaucrat and social effects, which have been shown to play an important role in determining individual attitudes toward corruption (Andvig and Moene, 1990; Tirole, 1996; and Gatti and others, 2003). The presence of these social effects, in turn, implies that incentives to fight corruption at the individual level can be low. Therefore, from a policy perspective, the existence of social effects implies that an effective fight against corruption often requires social sanctions against engaging in such activities. Transparency has a role to play in building and enabling anticorruption social effects.

\section{Conclusions}

Despite considerable reform attempts, many developing and transition countries continue to be characterized by pervasive and persistent rent capture, misgovernance, and public sector inefficiency. Country case studies and the existing literature advance different explanations 
and policy prescriptions, but most theoretical models and empirical studies generally focus on restricted aspects of the problem. In this paper, we develop a stylized analytical framework that reflects some realistic constraints faced by governments in these economies. In particular, we argue that this persistence reflects a stable equilibrium, resting on a social consensus among the different stakeholders. We augment existing principal-agent models of corruption by introducing a "minimum requirement constraint" and a budget constraint. However, in contrast to standard models, we do not specify incentive compatibility constraints, because of the failure of traditional incentives in many of these countries.

We argue that the ineffectiveness of traditional incentives in countering rent seeking, in conjunction with multiple binding constraints, can explain the persistence of corruption and policy distortions in these countries. In such an environment, we argue that "external" factors (to direct policy incentives, tools generally considered as decision variables in principalagent models) can play an important role in improving public outcomes. In particular, we examine the role of greater transparency - information production, disclosure, as well as the means to use it - in ameliorating the various constraints that impair public sector management, and as a result, assist in achieving better social outcomes. We summarize the evidence from existing empirical studies to illustrate how transparency can act at different levels: increasing the voice and bargaining power of the population vis-à-vis the agency, improving public agents' internal and public service motivations, facilitating controls, relaxing the budget constraint, and ameliorating the political environment. All of these can contribute to improving public services and outcomes.

Our analysis suggests that transparency is central for civil service, public expenditure, and fiscal management reforms, and provides a rationale for external donors, including IFIs, to promote greater transparency in the fiscal and political arenas. In addition to providing reforming governments with a credible "technology of commitment" to reforms (Devarajan and others, 2001), external partners may have an important role to play in promoting transparency in developing and transition countries. Donors could, for instance, reinforce citizens' voice, provide additional funds to relax the budget constraint (notably, for increasing basic wages in the public sector), and foster a more transparent public sector. IFIs, in particular, can direct their actions toward increasing fiscal transparency, both for facilitating the control of public funds and for providing information for citizens to exert their voice. Accrued benefits from fostering greater transparency should progressively push the high rent-seeking equilibrium toward one associated with better public outcomes. 


\section{Principal and Agent's Maximization Problems}

\section{Agent's Maximization Problem}

$$
\begin{gathered}
\max _{e_{2}} E(U)=w+\varepsilon\left(1-e_{2}+\theta\right)+(1-\alpha) e_{2}-C\left[(1-\alpha) e_{2}\right]^{2} \\
\text { s.t. } 1-e_{2}+\theta \geq Y(\text { MRC) }
\end{gathered}
$$

The Lagrangian for this problem can be written as:

$$
L=w+\varepsilon\left(1-e_{2}+\theta\right)+(1-\alpha) e_{2}-C\left[(1-\alpha) e_{2}\right]^{2}+\lambda\left(1-e_{2}+\theta-Y\right)+\mu\left(1-e_{2}\right)
$$

which gives the following Kuhn-Tucker conditions:

$$
\frac{\delta L}{\delta e_{2}}=-\varepsilon+1-\alpha-2 C(1-\alpha)^{2} e_{2}-\lambda-\mu \leq 0 \text { and } e_{2} \frac{\delta L}{\delta e_{2}}=0
$$

Note that (i) if $\alpha+\varepsilon \geq 1$, then $e_{2}=0$. Otherwise, $e_{2}=\frac{1-\alpha-\varepsilon-\lambda-\mu}{2 C(1-\alpha)^{2}} \geq 0$; (ii) if $\lambda=0, M R C$ is slack. From (1), we get $e_{2}=\frac{1-\alpha-\varepsilon-\mu}{2 C(1-\alpha)^{2}}$. Two cases may arise: (i) $\mu>0$, which implies that $e_{2}=1$, and $\theta>Y$, or (ii) more realistically, $\mu=0$ and $0<e_{2}^{*}=\frac{1-\alpha-\varepsilon}{2 C(1-\alpha)^{2}}<1$.

Given the latter assumption, we can show that $\frac{\partial e_{2}^{*}}{\partial C}=-\frac{1-\alpha-\varepsilon}{2 C^{2}(1-\alpha)^{2}}<0, \frac{\partial e_{2}^{*}}{\partial \varepsilon}=\frac{-1}{2 C(1-\alpha)^{2}}<0$, $\frac{\partial e_{2}^{*}}{\partial \alpha}=\frac{1-\alpha-2 \varepsilon}{2 C(1-\alpha)^{3}}><0$ and $e_{1}^{*}=1-e_{2}^{*}=1-\frac{1-\alpha-\varepsilon}{2 C(1-\alpha)^{2}}$. This implies that $\lim _{C \rightarrow 0} e_{2}^{*}=\infty \Leftrightarrow \lim _{C \rightarrow 0} e_{2}^{*}=1$ and $\lim _{C \rightarrow \infty} e_{2}^{*}=0$. As $0 \leq e_{2}^{*} \leq 1 \Leftrightarrow 0 \leq \frac{1-\alpha-\varepsilon}{2 C(1-\alpha)^{2}} \leq 1$, we must have $1-\alpha-\varepsilon \leq 2 C(1-\alpha)^{2}$. Therefore, the principal must increase $C$ above $C \geq \frac{1-\alpha-\varepsilon}{2(1-\alpha)^{2}}$ to implement a regime where $M R C$ is slack.

If, however, $\lambda>0, M R C$ is binding and $e_{2}^{M R}=1+\theta-Y$. From (1), we know that $\lambda+\mu=1-\alpha-\varepsilon-2 C(1-\alpha)^{2} e_{2}$. Two cases may arise: (i) $\mu>0$, which implies that $e_{2}=1$, and 
$\theta=Y$; (ii) more realistically, $\mu=0$ and $\lambda=1-\alpha-\varepsilon-2 C(1-\alpha)^{2}(1+\theta-Y)$. As $\lambda>0$, this may occur only if $C<\frac{1-\alpha-\varepsilon}{2(1-\alpha)^{2}(1+\theta-Y)}$.

Furthermore, the expected penalty if $M R C$ is slack can be written as:

$$
\Pi[C, R]=C\left[(1-\alpha) e_{2}\right]^{2}=\frac{1}{4 C}\left[1-\frac{\varepsilon}{1-\alpha}\right]^{2}
$$

The expected penalty if $M R C$ is binding is given by:

$\Pi[C, R]=C\left[(1-\alpha) e_{2}\right]^{2}=C[(1-\alpha)(1+\theta-Y)]^{2}$

Therefore, the agent's utility when $M R C$ is slack or binding, respectively, simplifies to:

$U^{*}=w+\varepsilon(1+\theta)+\frac{(1-\alpha-\varepsilon)^{2}}{2 C(1-\alpha)^{2}}$ and $U^{M R}=w+\varepsilon Y+(1-\alpha)(1+\theta-Y)[1-C(1-\alpha)(1+\theta-Y)]$.

\section{Principal's Maximization Problem}

s.t.

$$
\begin{gathered}
\max _{w, C} E(X)=1-e_{2}+\theta-w-C \\
w+\varepsilon\left(1-e_{2}+\theta\right)+(1-\alpha) e_{2}-\Pi(C, R) \geq u^{*} \\
w+C \leq B
\end{gathered}
$$

The Lagrangian for this problem can be written as:

$$
L=1-e_{2}+\theta-w-C+\lambda_{1}\left[w+\varepsilon\left(1-e_{2}+\theta\right)+(1-\alpha) e_{2}-\Pi(C, R)-u^{*}\right]+\lambda_{2}[B-w-C]
$$

The Kuhn-Tucker conditions for this problem can be written as:

$$
\begin{aligned}
& \frac{\partial L}{\partial C}=-\frac{\partial e_{2}}{\partial C}-1+\lambda_{1}\left[(1-\alpha-\varepsilon) \frac{\partial e_{2}}{\partial C}-\frac{\partial \Pi}{\partial C}\right]-\lambda_{2} \leq 0 \text { and } C \frac{\partial L}{\partial C}=0 \\
& \frac{\partial L}{\partial w}=-1+\lambda_{1}-\lambda_{2} \leq 0 \text { and } w \frac{\partial L}{\partial w}=0
\end{aligned}
$$


Note that (3) implies that $w>0$ only if $\lambda_{1}>0$, i.e. only if $P C$ is binding (then, $\lambda_{1}=1+\lambda_{2}$ ). Similarly, (2) implies that $C>0$ only if $\frac{\partial e_{2}}{\partial C}\left[\lambda_{1}(1-\alpha-\varepsilon)-1\right]=1+\lambda_{1} \frac{\partial \Pi}{\partial C}+\lambda_{2}$. Two cases are possible according to the agent's reaction function.

(A) If MRC is binding: $e_{2}^{M R}=1+\theta-Y$

Substituting into (2), we get: $\frac{\partial L}{\partial C}=-1-\lambda_{1} \frac{\partial \Pi}{\partial C}-\lambda_{2} \leq 0$ and $C \frac{\partial L}{\partial C}=0$, with $\frac{\partial P}{\partial C}=\left[(1-\alpha) e_{2}\right]^{2}=[(1-\alpha)(1+\theta-Y)]^{2} \geq 0$.

This implies that the principal will not exert controls $(C=0)$ and (2) holds with strict inequality. Two sub-cases are then possible:

(i) If $P C$ is slack: $\lambda_{1}=0$ and from (3) $w^{*}=0$. The agent's utility is $U=\varepsilon Y+(1-\alpha)(1+\theta-Y)=(1-\alpha)(1+\theta)-Y(1-\alpha-\varepsilon)$, and expected public output is $E(X)=Y$.

(ii) If $P C$ is binding: $\lambda_{1}>0$ and $w>0$; the principal increases wages until $w^{*}=u^{*}+Y(1-\alpha-\varepsilon)-(1-\alpha)(1+\theta)$, if this is compatible with $B C$ ( i.e. if $\left.w^{*} \leq B\right)$. Expected public output is given by $E(X)=Y-w^{*}=Y(\alpha+\varepsilon)+(1-\alpha)(1+\theta)-u^{*}$.

(B) If MRC is slack: $e_{2}^{*}=\frac{1-\alpha-\varepsilon}{2 C(1-\alpha)^{2}}$

From the agent's maximization problem above, we knew that this regime occurs when $C \geq \frac{1-\alpha-\varepsilon}{2(1-\alpha)^{2}}$. Therefore, (2) holds with equality. Furthermore, we get $\frac{\partial e_{2}^{*}}{\partial C}=-\frac{1-\alpha-\varepsilon}{2 C^{2}(1-\alpha)^{2}}$, $\Pi(C, R)=C\left[(1-\alpha) e_{2}\right]^{2}=\frac{(1-\alpha-\varepsilon)^{2}}{4 C(1-\alpha)^{2}}$ and $\frac{\partial \Pi}{\partial C}=-\frac{(1-\alpha-\varepsilon)^{2}}{4 C^{2}(1-\alpha)^{2}}$.

Substituting in (2), we get $\frac{1-\alpha-\varepsilon}{2 C^{2}(1-\alpha)^{2}}-1-\lambda_{1}\left[\frac{(1-\alpha-\varepsilon)^{2}}{4 C^{2}(1-\alpha)^{2}}\right]-\lambda_{2}=0$.

This gives rise to two possible sub-cases. 
(i) If $P C$ is slack, $\lambda_{1}=0$, and from (3), we have $w^{*}=0$. The agent's utility is given by $U=\varepsilon(1+\theta)+\frac{(1-\alpha-\varepsilon)^{2}}{4 C(1-\alpha)^{2}}$, with $C$ defined as follows in (a) and (b):

(a) If $B C$ is slack, $\lambda_{2}=0$, and from (2): $\frac{1-\alpha-\varepsilon}{2 C^{2}(1-\alpha)^{2}}=1$, so that the optimal control cost is $C^{*}=\sqrt{\frac{1-\alpha-\varepsilon}{2(1-\alpha)^{2}}}$, and $E(X)=1+\theta-\frac{\sqrt{2(1-\alpha-\varepsilon)}}{(1-\alpha)}$.

(b) If $B C$ is binding, $\lambda_{2}>0$, and from (2), we get $\frac{1-\alpha-\varepsilon}{2 C^{2}(1-\alpha)^{2}}=1+\lambda_{2}$. The optimal control $\operatorname{cost}$ is $\frac{1-\alpha-\varepsilon}{2(1-\alpha)^{2}}<B=C^{* *}=\sqrt{\frac{1-\alpha-\varepsilon}{2(1-\alpha)^{2}\left(1+\lambda_{2}\right)}}<\sqrt{\frac{1-\alpha-\varepsilon}{2(1-\alpha)^{2}}}$, and $E(X)=1+\theta-\frac{1-\alpha-\varepsilon}{2 B(1-\alpha)^{2}}-B$.

Note that the control cost when $B C$ is binding is obviously lower than when it is not. Therefore, the agent will choose a higher level of rent capture when $B C$ is binding.

(ii) If $P C$ is binding, $\lambda_{1}>0$ and (notwithstanding corner solutions) $w^{*}>0$. The principal then determines wage and control costs such that $w^{*}+\varepsilon(1+\theta)+\frac{(1-\alpha-\varepsilon)^{2}}{4 C^{*}(1-\alpha)^{2}}=u^{*}$.

(a) If $B C$ is slack, $\lambda_{2}=0$, and from (3) we get $\lambda_{1}=1$. From (2), we get

$$
\frac{1-\alpha-\varepsilon}{2 C^{2}(1-\alpha)^{2}}=1+\left[\frac{1-\alpha-\varepsilon}{2 C(1-\alpha)}\right]^{2} \text {. We thus find } C^{* * *}=\frac{\sqrt{(1-\alpha-\varepsilon)(1+\alpha+\varepsilon)}}{2(1-\alpha)} \text {. }
$$

By assumption, to have an agency problem, $\alpha+\varepsilon<1$. Therefore, $C^{* * *}<C^{*}$, which implies that the control cost when $P C$ is binding is lower than when it is slack. Therefore, the agent will choose a higher level of rent capture when $P C$ is binding.

Furthermore, from $P C$ we find that $w^{*}=u^{*}-\varepsilon(1+\theta)-\frac{(1-\alpha-\varepsilon)^{3 / 2}}{2(1-\alpha) \sqrt{1+\alpha+\varepsilon}}$.

Substituting these values of $C$ and $w$, and simplifying, we can show that expected output is $E(X)=(1+\theta)(1+\varepsilon)-u^{*}$. 
(b) If $B C$ is binding, $\lambda_{2}>0$, so that $w+C=B$ and from (3), $\lambda_{1}=1+\lambda_{2}>1$. From (2) we get:

$$
\begin{aligned}
& \frac{1-\alpha-\varepsilon}{2 C^{2}(1-\alpha)^{2}}=\lambda_{1}\left[1+\frac{(1-\alpha-\varepsilon)^{2}}{4 C^{2}(1-\alpha)^{2}}\right] \Leftrightarrow C^{2}=\frac{2(1-\alpha-\varepsilon)-\lambda_{1}(1-\alpha-\varepsilon)^{2}}{4 \lambda_{1}(1-\alpha)^{2}}, \text { so that } \\
& C^{* * * *}=\frac{\sqrt{(1-\alpha-\varepsilon)\left[2-\lambda_{1}(1-\alpha-\varepsilon)\right]}}{2(1-\alpha) \sqrt{\lambda_{1}}}=B-w^{*} .
\end{aligned}
$$

Knowing that $1<\lambda_{1} \leq \frac{2}{1-\alpha-\varepsilon}$, we can show that $C^{* * * *}<C^{*}$ and $C^{* * * *}<C^{* * *}$, which implies that a binding $B C$ reduces the control by the principal, which in turn implies higher rent capture by the agent.

Furthermore, from $P C$, we get

$$
w^{*}=u^{*}-\varepsilon(1+\theta)-\frac{(1-\alpha-\varepsilon)^{3 / 2}}{2(1-\alpha) \sqrt{\left(2 / \lambda_{1}\right)-(1-\alpha-\varepsilon)}} .
$$

The expected output is given by $E(X)=1+\theta-\frac{1-\alpha-\varepsilon}{2\left(B-w^{*}\right)(1-\alpha)^{2}}-B$. 


\section{REFERENCES}

Acemoglu, D., and T. Verdier, 2000, "The Choice Between Market Failures and Corruption," American Economic Review, Vol. 90, pp. 194-211.

Ahrend, R., 2002, “Press Freedom, Human Capital and Corruption,” DELTA Working Papers 2002-11, (Paris: DELTA).

Akerlof, G., 1982, “Labor Contracts as Partial Gift Exchanges,” Quarterly Journal of Economics, Vol. 97(4), pp. 543-569.

Andvig, J., and K. Moene, 1990, "How Corruption May Corrupt," Journal of Economic Behavior and Organization, Vol. 13, pp. 63-76.

Bac, M., 1996, “Corruption and Supervision Costs in Hierarchies," Journal of Comparative Economics 22(2), pp. 99-118.

Bako-Arifari, N., 2001, "La corruption au port de Cotonou : Douaniers et Intermédiaires," Politique Africaine 83, pp. 38-58.

Banerjee, A., 1997, “A Theory of Misgovernance,” Quarterly Journal of Economics, Vol. 112(4), pp. 1289-1332.

Basu, K., S. Bhattacharya, and S. Misra, 1992, "Notes on Bribery and the Control of Corruption,” Journal of Public Economics, Vol. 48, pp. 349-359.

Becker, G., and G. Stigler, 1974, "Law Enforcement, Malfeasance, and Compensation of Enforcers," Journal of Legal Studies, Vol. 1, pp. 1-18.

Besley, T., and R. Burgess, 2002, “The Political Economy of Government Responsiveness: Theory and Evidence from India," Quarterly Journal of Economics, Vol. 117(4).

Besley, T., and J. McLaren, 1993, "Taxes and Bribery: the Role of Wage Incentives," Economic Journal, Vol. 103 , pp. 119-141.

Bhagwati, J., 1982, "Directly Unproductive, Profit-seeking (DUP) Activities," Journal of Political Economy, Vol. 90(5), pp. 988-1002.

Blundo, G., and J.-P. Olivier de Sardan, 2001, "La Corruption Quotidienne en Afrique de l'Ouest," Politique Africaine Vol. 83, pp. 8-37.

Blundo, G., 2001, “ Dessus-de-table-La Corruption Quotidienne dans la Passation des Marchés Publics Locaux au Sénégal,” Politique Africaine, Vol. 83, pp. 98-114. 
Broadman, H., and F. Recanatini, Francesca, 2002, "Corruption and Policy: Back to the Roots," Journal of Policy Reform, Vol. 5 (1), pp. 37-49.

Brunetti, A., and B. Weder, 2003, “A Free Press is Bad News for Corruption,” Journal of Public Economic, Vol. 87, pp. 1801-1824.

Buchanan, J., R. Tollison, and G.Tullock (eds), 1980, Toward a Theory of the Rent-Seeking Society (College Station: Texas A\&M University Press).

Campos, E., and S. Pradhan, 1996, "Budgetary Institutions and Expenditure Outcomes : Binding Governments to Fiscal Performance," World Bank Policy Research Working Paper 1646, (Washington: The World Bank).

Cappelli, P., and K. Chauvin, 1991, "An Interplant Test of the Efficiency Wage Hypothesis," Quarterly Journal of Economics Vol. 106, pp. 769-788.

Chakraborty, S., and E. Dabla-Norris, 2005, "Rent Seeking," IMF Staff Papers (forthcoming).

Chomitz, K., G. Setiadi, A. Azwar, and N. Ismail Widiyarti, 1998, "What Do Doctors Want?: Developing Incentives for Doctors to Serve in Indonesia's Rural and Remote Areas," World Bank; Policy Research Working Paper 1888, (Washington: The World Bank).

Dabla-Norris, E., and S. Freeman, 2004, "Enforcement of Property Rights and Underdevelopment," Review of Development Economics, Vol. 8, No. 3, pp. 391405.

Dabla-Norris, E., 2002, “A Game-Theoretic Analysis of Corruption in Bureaucracies," in G. Abed and S. Gupta (ed.) Governance, Macroeconomics, and the IMF, (Washington: International Monetary Fund).

Damania, R., P. Fredriksson, and M. Mani, 2003, "The Persistence of Corruption and Regulatory Compliance Failures: Theory and Evidence," Public Choice, Vol. 121 ( 3), pp. 363-390.

Danninger, S., M. Cangiano, and A. Kyobe, 2005, "The Political Economy of RevenueForecasting Experience from Low Income Countries," IMF Working Paper 05/2 (Washington: International Monetary Fund).

Davis, J., 2004, “Corruption in Public Service Delivery: Experience from South Asia's Water and Sanitation Sector," World Development, Vol. 32 (1), pp. 53-71.

Devarajan, S., D. Dollar, and T. Holmgren (eds), 2001, Aid and Reform in Africa. Lessons from Ten Case Studies (Washington: The World Bank). 
Dia, M., 1996, “Africa’ s Management in the 1990s and Beyond: Reconciling Indigenous and Transplanted Institutions," Directions in Development (Washington: The World Bank).

Dickens, William, Lawrence Katz, Kevin Lang, and Lawrence Summers, 1989, "Employee Crime and the Monitoring Puzzle," Journal of Labor Economics 7 (July), pp. 31-347.

Di Tella, R., and E. Schargrodsky, 2002, "Political and Economic Incentives During an Anticorruption Crackdown," in D. Della Porta and S. Rose-Ackerman (Eds.), Corrupt Exchanges: Empirical Themes in the Politics and Political Economy of Corruption (Baden-Baden: Nomos Verlagsgesellschaft).

Easterly, W., 2001, The Elusive Quest for Growth. Economists' Adventures and Misadventures in the Tropics, (Cambridge: MIT Press).

Gatti, R., S. Paternostro, and J. Rigolini, 2003, "Individual Attitudes toward Corruption: Do Social Effects Matter?," World Bank Policy Research Working Paper 3122 (Washington: The World Bank).

Goldsmith, A., J. Veum, and W. Darity, Jr., 2000, "Working Hard for the Money? Efficiency Wages and Worker Effort," Journal of Economic Psychology 21(4), pp. 351-385.

Heller, P., 2005, “Understanding Fiscal Space,” IMF Policy Discussion Paper No. 05/4 (Washington: International Monetary Fund).

Holmström, B., 1979, "Moral Hazard and Observability," Bell Journal of Economics, Vol. 10(1), pp 74-91.

Holmström, B., and P. Milgrom, 1991, "Multi-Task Principal-Agent Analyzes: Incentive Contracts, Asset Ownership and Job Design," Journal of Law, Economics and Organization, Vol. 7, pp. 24-52.

International Monetary Fund, 1998, IMF Survey 27(8) (April 27).

International Monetary Fund, 2003, World Economic Outlook (April).

International Monetary Fund, 2005, World Economic Outlook (September).

Kaufmann, D., G. Mehrez, and T. Gurgur, 2002, "Voice or Public Sector Management? An Empirical Investigation of Public Sector Performance based on a Survey of Public Officials," World Bank Policy Research Working Paper (unpublished; Washington: World Bank)

Kaufmann, D., and A. Kraay, 2002, “Growth without Governance,” World Bank Policy Research Working Paper 2928 (Washington: The World Bank). 
Keefer, P., 2005, "Democratization and Clientelism: Why Are Young Democracies Badly Governed?," World Bank Policy Research Working Paper 3594 (Washington: The World Bank).

Keefer, P., and S. Khemani, 2005, "Democracy, Public Expenditures, and the Poor: Understanding Political Incentives for Providing Public Services," The World Bank Research Observer, Vol. 20(1), pp. 1-27.

Keefer, P., and R. Vlaicu, 2004, “Democracy, Credibility and Clientelism,” World Bank Policy Research Working Paper 3472 (Washington: The World Bank).

Laffont, J., and D. Martimort, 2002, The Theory of Incentives. The Principal-Agent Model, (New Jersey: Princeton University Press).

Leruth, L., and E. Paul, 2006, "A Principal-Agent Theory Approach to Public Expenditure Management in Developing Countries," IMF Working Paper (forthcoming; Washington: International Monetary Fund).

Lienert, I., 2003, “A Comparison Between Two Public Expenditure Management Systems in Africa,” IMF Working Paper No. 03/2 (Washington: International Monetary Fund).

Martens, B., with U. Mummert, P. Murrell, and P. Seabright, 2002, The Institutional Economics of Foreign Aid, (Cambridge: Cambridge University Press).

Mauro, P., 1995, “Corruption and Growth," Quarterly Journal of Economics, Vol. 110 (3), pp. 681-712. , 2004, "The Persistence of Corruption and Slow Economic Growth," IMF Staff Papers, Vol. 51 (1), pp. 1-18.

Mauss, M., 1923-1924, “Essai Sur le Don. Forme et Raison de 1'échange Dans les Sociétés primitives," Année Sociologique, seconde série.

Médard, J.-F., 1992, "Le Big Man en Afrique : Esquisse d'analyse du Politicien Entrepreneur," L'année Sociologique, 42, pp. 169-172.

Mookherjee, D., L. Png, 1995, “Corruptible Law Enforcers: How Should They be Compensated," The Economic Journal, Vol. 105, pp. 145-159.

Moussa, Y., 2004, "Public Expenditure Management in Francophone Africa: A CrossCountry Analysis," IMF Working Paper 04/42 (Washington: International Monetary Fund). 
Moynihan, D., and S. Pandey, 2005, “The Role of Organizations in Fostering Public Service Motivation," Public Administration Review (forthcoming).

Niskanen, W., 1971, Bureaucracy and Representative Government, (Chicago: Aldine/Atherton Press).

Olken, B., 2005, "Monitoring Corruption: Evidence from a Field Experiment in Indonesia,' (unpublished; Cambridge, Massachusetts: National Bureau of Economic Research).

Paul, E., and M. Robinson, 2005, "Performance Budgeting, Motivation, and Incentives" (forthcoming, International Monetary Fund).

Petrie, M., 2003, "Promoting Fiscal Transparency: The Complementary Roles of the IMF, Financial Markets, and Civil Society," IMF Working Paper 03/199 (Washington: International Monetary Fund).

Poncelet, M., G. Pirotte, G. Stangherlin, and E. Sindayihebura, 2005, Les ONG en Villes Africaines, (Louvain-La-Neuve: Academia).

Rauch, J., 2001, "Leadership Selection, Internal Promotion, and Bureaucratic Corruption in Less Developed Politics," Canadian Journal of Economics, Vol. 34 (1), pp. 240-258.

Rauch, J., and P. Evans, 2000, "Bureaucratic Structure and Bureaucratic Performance in Less Developed Countries," Journal of Public Economics, Vol. 75 (1), pp. 49-71.

Recanatini, Francesca, Alessandro Prati, and Guido Tabellini, 2005, "Why Are Some Public Agencies less Corrupt than Others? Lessons for Institutional Reform from Survey Data," Jacques Polak Sixth Annual Research Conference, (Washington: International Monetary Fund).

Reinikka, R., and J. Svensson, 2004, "Local Capture: Evidence from a Central Government Transfer Program in Uganda," The Quarterly Journal of Economics, Vol. 119 (2), pp. $679-705$.

, 2005, "Fighting Corruption to Improve Schooling: Evidence from a Newspaper Campaign in Uganda," Journal of European Economic Association, (forthcoming).

Robinson, J., and T. Verdier, 2002, “The Political Economy of Clientelism,” CEPR Discussion Paper 3205, (London: Center for Economic and Policy Research).

Rose-Ackerman S., 1978, Corruption: A Study in Political Economy, (New York: Academic Press).

Sarte, P., 2001, "Rent-seeking Bureaucracies and Oversight in a Simple Growth Model," Journal of Economic Dynamics and Control, Vol. 25, pp. 1345-1365. 
Shleifer, A., and R. Vishny, 1993, “Corruption," Quarterly Journal of Economics, Vol. 108, pp. 599-617.

Svensson, J., 2003, "Who Must Pay Bribes and How Much,” Quarterly Journal of Economics, Vol. 118 (1), pp. 207-230.

Tirole, Jean, 1996, “A Theory of Collective Reputations," Review of Economic Studies, Vol. 63, pp. 1-22.

Van Rijckeghem, C., and B. Weder, 1997. "Corruption and the Rate of Temptation-Do Low Wages in the Civil Service Cause Corruption?," IMF Working Papers 97/73 (Washington: International Monetary Fund).

World Bank, 1997, Helping Countries Combat Corruption: The Role of the World Bank. (Washington: The World Bank). , 2000, "Bolivia. From Patronage to a Professional State. Bolivia Institutional and Governance Review," Report No. 20115-BO, (Washington: The World Bank). 